\title{
Broken needle during spinal anesthesia: an avoidable complication
}

This article was published in the following Dove Press journal:

Local and Regional Anesthesia

\author{
Rawéléguinbasba Armel \\ Flavien Kaboré \\ Ibrahim Alain Traore ${ }^{2}$ \\ Salah Idriss Séif Traore ${ }^{3}$ \\ Cheik Tidiane Hafi Wind- \\ Pouiré Bougouma' \\ Pascal Augustin 4 \\ Aboudoul-Fataou Ouro- \\ Bang'na Maman \\ 'Department of Anesthesia, \\ University Hospital Blaise Comparoé, \\ Ouagadougou, Burkina Faso; \\ ${ }^{2}$ Department of Anesthesia, Uiversity \\ Hospital Sourou Sanou, Bobo \\ Dioulasso, Burkina Faso; ${ }^{3}$ Department \\ of Anesthesia, District Hospital of \\ Bogodogo, Ouagadougou, Burkina \\ Faso; ${ }^{4}$ Department of Anesthesia, \\ Intercommunity Hospital of Meulan, \\ Les Mureaux, Meulan en Yvelines, \\ France; ${ }^{5}$ Department of Anesthesia, \\ Ales-en-Cévennes Hospital, Alès-en- \\ Cévennes, France
}

\begin{abstract}
The occurrence of a needle breaking is a very rare complication of spinal anesthesia (SA). We report a case of a broken spinal needle occurring in a morbid obese pregnant woman during SA indicated for an emergent cesarean section. Multiple puncture attempts due to difficult identification of lumbar spine, associated with an inadequate use of the introducer, contributed to this complication. The recognition of predictive factors for difficult neuraxial anesthesia, the use of ultrasound in obese patients, and a properly executed technique may have allowed avoiding this complication.
\end{abstract}

Keywords: spinal anesthesia, needle breaking, cesarean section, obesity

\section{Introduction}

Spinal anesthesia (SA) is currently the preferred technique for cesarean delivery. ${ }^{1}$ SA is associated with postdural puncture headache. The intensity and the frequency of this complication is decreased by the use of small caliber needles. ${ }^{2,3}$ However, the smaller the caliber of the needle, the greater the risk of difficult puncture is, with needle bending and difficulty to ascertain an adequate direction of the needle, especially in obese patients. Introducer helps to circumvent this drawback. Nevertheless, the use of a metal introducer induces a risk of plicature or even breaking of the spinal needle. ${ }^{2}$ We report a case of a broken spinal needle occurring in a morbid obese pregnant woman during a difficult SA indicated for an emergent cesarean section (CS). An informed consent to publish her case was obtained from the patient.

\section{Case report}

A 30-year-old, gravida 3, para 2, 36-week pregnant woman, with a body mass index of $42 \mathrm{~kg} / \mathrm{m}^{2}$ was admitted for pre-eclampsia and abnormal fetal heart rate. She had a previous CS under epidural anesthesia. The clinical examination at admission revealed severe hypertension (blood pressure at $160 / 100 \mathrm{mmHg}$ ) and an epigastric pain. There was no significant edema or recent weight gain. There was no headache, and osteotendinous reflexes were normal. Laboratory assessment found proteinuria $>0.3 \mathrm{~g} / \mathrm{L}$. Creatinine blood level, liver enzymes, and platelets count were normal. CS under SA was indicated.

The patient was in the sitting position. The traditional medial approach was used to perform the SA. There was only one skin puncture, with four unsuccessful attempts with multiple changings of the needle direction, at the interspinous level L3-L4 by a senior anesthesiologist. A $90-\mathrm{mm}, 25$-gage Whitacre needle with an introducer was
Correspondence: Rawéléguinbasba Armel Flavien Kaboré

Service d'Anesthésie, $\mathrm{CHU}$ Blaise

Compaoré, II BP 104 Ouagadougou

CMS II, Burkina Faso

Email kflavien72@yahoo.fr 
used. The anesthesiologist did not feel any resistance that would have indicated that he reached the interspinous ligament. At the fourth attempt, the needle was severed while removing it through the introducer, which was not mobilized. The stylette was not broken because it had been removed just before the needle mobilization. The severed part of the needle remained in an undetermined deep location. The patient was informed of the incident. Considering the morbid obesity, SA was considered safer, and it was chosen again. Another puncture was attempted at the space underneath, through an introducer with an identical needle. This attempt was immediately successful. Ten milligrams of hyperbaric bupivacaine associated with $2.5 \mu \mathrm{m}$ of sufentanil were injected. The CS was uneventful.

A CT scan of the lumbar spine performed on first postoperative day revealed a $5 \mathrm{~cm}$ metallic placated needle (Figure 1). The needle was located within the erector spinae muscle at a depth of $7 \mathrm{~cm}$ from the skin, $1 \mathrm{~cm}$ to the right of the L3 spinous process, and $1 \mathrm{~cm}$ from the right posterior articular mass (Figure 2). Extraction of the metal fragment was performed by a neurosurgeon by direct surgical approach under general anesthesia at 13th postoperative day. The procedure and the postoperative course were uneventful. Follow-up at 6 months did not reveal any local complication.

\section{Discussion}

The difficulties of dural puncture resulting in multiple punctures increase the risk of plication and breaking of the SA needle. ${ }^{2-5}$ This risk is probably increased in emergency situations or in obese patients. ${ }^{6}$ In order to reduce this risk, it is advisable not to continue the puncture if there is abnor-

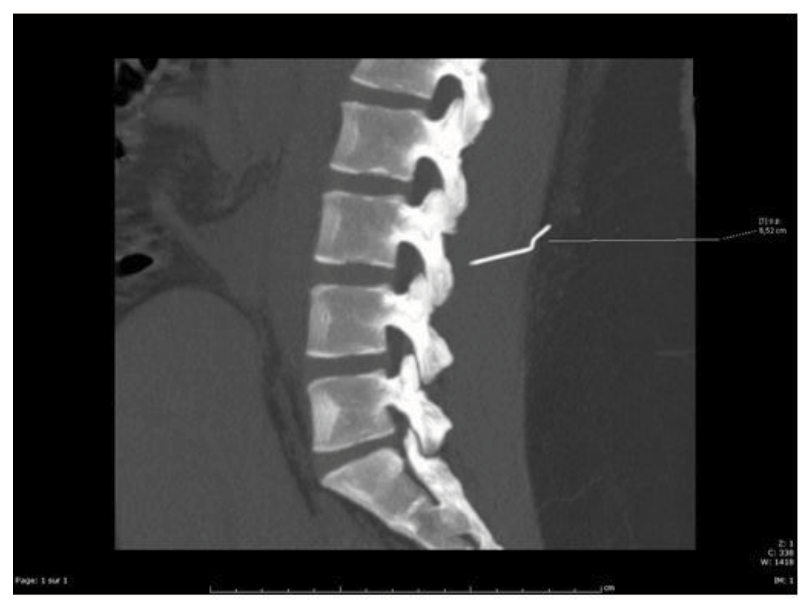

Figure I A lumbar spine CT scan.

Note: Sagittal plane image showing the broken needle at the L3 level - at a depth of $7 \mathrm{~cm}$ from the skin. mal resistance or a bone contact, not to withdraw the needle or to change its direction through the introducer without mobilizing it. ${ }^{7}$ In fact, the introducer bevel may sever the needle while removing the needle through the introducer. Therefore, it is advocated to always mobilize simultaneously the introducer and the needle. Many anesthesiologists do not respect this rule of mobilizing the introducer for withdrawals and changes of direction of the SA needle. ${ }^{8}$ In our case, there were two predicting factors of difficult puncture: emergent $\mathrm{CS}$ and morbid obesity. The numerous unsuccessful attempts of dural puncture resulted in a plication of the needle, which was weakened, and then severed by the introducer. The mobilization of the needle through the non mobilized introducer favors, first, the bending and the deformation of the needle, and then, the breaking of the needle severed by the blunt end of the introducer. ${ }^{8,9}$ Some cases of needle breaking not related to the introducer have been described. ${ }^{10,11}$ Some authors propose the use of larger puncture needles taking into account the benefit and risk balance of such needles. ${ }^{12}$

Decreasing the number of puncture attempts lowers the risk of needle damaging. Obesity makes anatomical identification of the skin puncture site difficult, which could lead to an incorrect trajectory of the needle. Ultrasound recognition before puncture decreases the number of punctures and abnormal pathways in obese patients. ${ }^{13,14}$ Therefore, the risk of

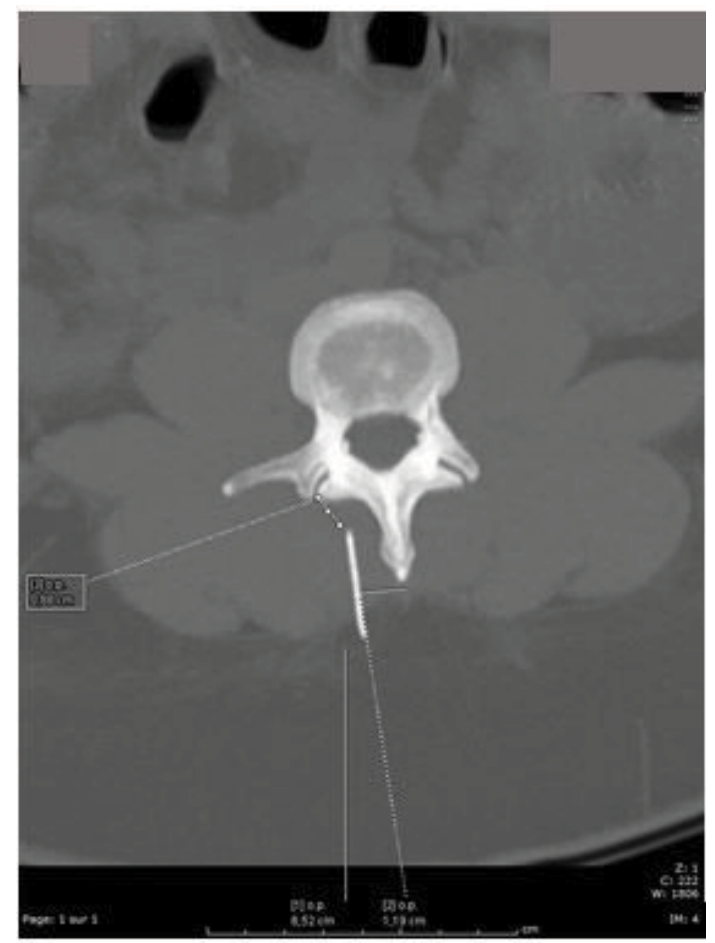

Figure 2 A lumbar spine CT scan.

Note: Horizontal plane image showing the needle in the right paravertebral space within the erector spinae muscle. 
alteration of the needle may be reduced. In our case, CT scan demonstrates the aberrant path of the needle, demonstrating the absence of recognition of bone structures and interspinous spaces. This may have been overcome by the use of ultrasound.

SA may remain the first-line option in the absence of contraindication. Nevertheless, the risk of unsuccessful puncture or supplemental complication should have made consider the choice of general anesthesia (GA). Taking into account benefits and risks of each option, we decided to proceed to another attempt of SA, mainly because of the morbid obesity. ${ }^{15}$ Even if it seems appropriate to continue the puncture attempt at another interspinous space level, ${ }^{8} \mathrm{GA}$ as an alternative should be at least discussed. Considering the risk of definitive neurological damage in case of intradural migration of the fragment, the removal of the needle fragment should be considered as soon as possible. ${ }^{8}$

\section{Conclusion}

The breaking of a SA needle is a rare incident of multifactorial causes. The main cause is the inadequate use of the introducer. Beside the proper mobilization of the introducer, it is essential in case of patients with risks of difficult punctures to consider the use of ultrasound, especially when the first lumbar puncture failed, or in presence of risk factors for difficult lumbar puncture.

\section{Disclosure}

The authors report no conflicts of interest in this work.

\section{References}

1. Practice Guidelines for Obstetric Anesthesia: an updated report by the American Society of Anesthesiologists Task Force on Obstetric Anesthesia and the Society for Obstetric Anesthesia and Perinatology. Anesthesiology. 2016;124(2):270-300.

2. Thomsen AF, Nilsson CG. Broken small-gauge spinal needle. Anesth Analg. 1997;85(1):230-231.

3. Lambert DH, Hurley RJ, Hertwig L, Datta S. Role of needle gauge and tip configuration in the production of lumbar puncture headache. Reg Anesth. 1997;22(1):66-72.

4. Abou-Shameh MA, Lyons G, Roa A, Mushtaque S. Broken needle complicating spinal anaesthesia. Int J Obstet Anesth. 2006;15(2):178-179.

5. Thomsen AF, Nilsson CG. Broken small-gauge spinal needle. Anesth Analg. 1997;85(1):230-231.

6. Greenway MW, Vickers R. Broken micro-tip spinal needle. Int J Obstet Anesth. 2009;18(3):295-296.

7. Lonnée H, Fasting S. Removal of a fractured spinal needle fragment six months after caesarean section. Int J Obstet Anesth. 2014;23(1):95-96.

8. Martinello C, Rubio R, Hurwitz E, Simon M, Vadhera RB. Broken spinal needle: case report and review of the literature. J Clin Anesth. 2014;26(4):321-324.

9. Eng M, Zorotovich RA. Broken-needle complication with a disposable spinal introducer. Anesthesiology. 1977;46(2):147-148.

10. Rieg AD, Dortgolz A, Macko S, Rossaint R, Schälte G. In situ broken 27-gauge spinal needle in a repeated caesarean delivery: case report and literature review. Anaesthesist. 2017;66(2):115-121.

11. Hershan DB, Rosner HL. An unusual complication of epidural analgesia in a morbidly obese parturient. Anesth Analg. 1996;82(1):217-218.

12. Gentili ME, Nicol JB, Enel D, Marret E. Recovery of a broken spinal needle. Reg Anesth Pain Med. 2006;31(2):18.

13. Carvalho JCA. Ultrasound-facilitated epidurals and spinals in obstetrics. Anesthesiol Clin. 2008;26(1):145-158.

14. Sahin T, Balaban O, Sahin L, Solak M, Toker K. A randomized controlled trial of preinsertion ultrasound guidance for spinal anaesthesia in pregnancy: outcomes among obese and lean parturients. $J$ Anesth. 2014;28(3):413-419.

15. Lamon AM, Habib AS. Managing anesthesia for cesarean section in obese patients: current perspectives. Local Reg Anesth. 2016;9:45-57.
Local and Regional Anesthesia

\section{Publish your work in this journal}

Local and Regional Anesthesia is an international, peer-reviewed, open access journal publishing on the development, pharmacology, delivery and targeting and clinical use of local and regional anesthetics and analgesics. The journal is included in PubMed, and welcomes submitted papers covering original research, basic science, clinical studies,

\section{Dovepress}

reviews and evaluations, guidelines, expert opinion and commentary, case reports and extended reports. The manuscript management system is completely online and includes a very quick and fair peer-review system, which is all easy to use. Visit http://www.dovepress.com/ testimonials.php to read real quotes from published authors. 